Publish by: Library of STKIP PGRI Sumatera Barat

E-ISSN : 2775-5770

Vol. 1 No. 4 (November 2021) (658-666)

http://ejournal.stkip-pgri-sumbar.ac.id/index.php/horizon

\title{
ANALISIS KEMAMPUAN PEMAHAMAN KONSEP MATEMATIS SISWA PADA PEMBELAJARAN MATEMATIKA KELAS XI IIS SMA PGRI 3 PADANG
}

Ibnu S, Radhya Yusri, Lucky Heriyanti Jufri

Program Studi Pendidikan Matematika STKIP PGRI Sumatera Barat ibnu.s1996@gmail.com

Submitted: 06-09-2021, Reviewed: 16-09-2021, Accepted: 03-11-2021

\begin{abstract}
This research is motivated by the low ability students' mathematical concepts in learning mathematics. The purpose of this research to find out how mathematical ability if class XII IS SMA students is PGRI 3 Padang. The subjects of this study were students of class XII IIS SMA PGRI 3 Padang, totalling 19 students. The research method used is descriptive method using qualitative approach. The instrument used in this study was a test of the abiliy to understand concepts in the form of 4 questions in the form of descriptions and interviews. The test results were analysed based on indicators of concept understanding. The results of this study indicate that ability to understand students' mathematical concepts based on the analysis of each indicator on concept understanding is as follows the indicator restates a concept in the medium category, classifies objects according to certain properties (according to the concept) is in the high category, providing examples and non-axamples of concepts that are in the poor category, presenting concepts in the form of mathematical representations are in the poor category. Developing the necessary or sufficient conditions for a concept to be in the medium category, and applying the concept or problem-solving algorithm to the low category.
\end{abstract}

\section{Keywords: Mathematics Learning, Ability to Understand Mathematical Concepts, Test Validity.}

\section{PENDAHULUAN}

Matematika adalah ilmu yang sangat penting utuk dipelajari, salah satu tujuan pembelajaran matematika di sekolah adalah agar siswa mampu memahami konsep matematika. Hal ini dikarenakan dengan menumbuhkan pemahaman pada setiap kegiatan belajar matematika akan mengembangkan pengetahuan matematika yang dimiliki oleh siswa itu sendiri (Fitri, 2019). Pembelajaran merupakan proses interaksi antara siswa dengan pengajar dan sumber belajar pada suatu lingkungan belajar (Rosita, 2014).

Menurut Nia Gardenia (2016) menyatakan bahwa "Tujuan pembelajaran matematika yang 


\section{Jupana HORIZON}

PENDIDIKAN
JURNAL HORIZON PENDIDIKAN

Publish by: Library of STKIP PGRI Sumatera Barat

E-ISSN : 2775-5770

Vol. 1 No. 4 (November 2021) (658-666)

http://ejournal.stkip-pgri-sumbar.ac.id/index.php/horizon hendak dicapai kemampuan

pemahaman konsep menjadi

kompetensi yang esensial dan merupakan visi dari belajar matematika. Tujuan pembelajaran matematika adalah agar siswa dapat:

(1) Memahami konsep matematika dalam pemecahan masalah.

Menggunakan pola sebagai dugaan dalam penyelesaian masalah. (3) Menggunakan penalaran dalam memecahkan masalah dalam kehidupan sehari-hari (dunia nyata).

(4) Mengkomunikasikan gagasan untuk memperjelas keadaan atau masalah. (5) Memiliki sikap menghargai kegunaan matematika dalam pemecahan masalah (Kemendikbud, 2014). Berdasarkan kutipan di atas, salah satu kemampuan yang harus dikuasai siswa adalah pemahaman konsep.

Pemahaman konsep menjadi dasar yang sangat penting dalam melakukan pemecahan masalah. jika siswa telah memahami konsepkonsep dasar matematika, siswa akan memudahkan siswa dalam mempelajari konsep-konsep matematika berikutnya yang lebih kompleks. Oleh karena itu, untuk memahami suatu konsep matematika siswa terlebih dahulu harus memahami konsep yang menjadi prasyarat dari materi tersebut. Hal ini karena konsep dalam matematika saling berhubungan satu sama lain (Yusri, 2017).

Pemahaman konsep adalah penguasaan sejumlah materi pembelajaran, dimana siswa tidak hanya mengenal dan mengetahui tetapi mampu mengungkapkan kembali dalam bahasa yang mudah dimengerti serta mampu mengaplikasikannya kembali (Rosmawati, 2008). Pemahaman konsep merupakan kemampuan siswa untuk dapat mengerti konsep yang diajarkan guru dengan menggunakan kata-kata sendiri (Suraji, 2017). Oleh sebab itu, sudah seharusnya kemampuan pemahaman konsep dikuasai oleh siswa dalam pembelajaran matematika.

Pentingnya kemampuan pemahaman konsep oleh siswa dikemukakan Santrock (Ai Mulyani, 2018) pemahaman konsep adalah aspek kunci dari pembelajaran. Menurut O'Connel (Ai Mulyani, 2018) dengan pemahaman 
HORIZON

PENDIDIKAN
JURNAL HORIZON PENDIDIKAN

Publish by: Library of STKIP PGRI Sumatera Barat

E-ISSN : 2775-5770

Vol. 1 No. 4 (November 2021) (658-666)

http://ejournal.stkip-pgri-sumbar.ac.id/index.php/horizon matematis, siswa akan lebih mudah dalam memecahkan permasalahan karena siswa akan mampu mengaitkan serta memecahkan permasalahan tersebut dengan berbekal konsep yang sudah di pahaminya. Pemahaman konsep matematika sangat penting karena salah satu tujuan dari pembelajaran matematika, pemahaman konsep juga dapat membantu siswa untuk tidak hanya sekedar menghafal rumus, tetapi dapat mengerti benar apa makna dalam pembelajaran matematika.

Indikator menurut (Shadiq, 2009) adalah sebagai berikut: 1) menyatakan ulang sebuah konsep, 2) mengklasifikasikan objek-objek menurut sifat-sifat tertentu (sesuai dengan konsepnya), 3) memberikan contoh dan non contoh dari konsep, 4) menyajikan konsep dalam bentuk representasi matematis, 5) mengembangkan syarat perlu atau syarat cukup dari suatu konsep, 6) mengaplikasikan konsep atau algoritma pemecahan masalah.

Kemampuan pemahaman konsep siswa akan berpengaruh pada keadaan sekarang, apalagi dimasa pandemi Covid-19 yang terjadi di Indonesia sejak tahun 2020 berdampak pada berbagai bidang dan sektor. Dalam bidang pendidikan, Covid-19 juga mengubah model pembelajaran secara drastic. Seluruh kegiatan pembelajaran dilakukan secara Daring mulai tingkat sekolah dasar sampai perguruan tinggi dimana mengharuskan siswa belajar dirumah dengan menerapkan pembelajaran secara Daring, yaitu pembelajaran yang menuntut siswa belajar mandiri untuk meningkatkan pemahaman konsep.

Berdasarkan hasil observasi dan wawancara yang dilakukan pada pembelajaran matematika melalui aplikasi Zoom kelas XI IIS SMA PGRI 3 Padang diperoleh informasi bahwa pelaksanaan pembelajaran online berjalan dengan baik, tetapi, siswa tidak terbiasa dengan proses pembelajaran Daring apalagi dihadapkan dengan pembelajran matematika, kendala pada umumnya dalam pembelajaran Daring baik guru maupun siswa, kendala terutama tidak semua siswa bisa ikut dalam pembelajaran Daring dikarenakan tidak mempunyai ponsel 


\section{( HORIZON} PENDIDIKAN
JURNAL HORIZON PENDIDIKAN

Publish by: Library of STKIP PGRI Sumatera Barat

E-ISSN : 2775-5770

Vol. 1 No. 4 (November 2021) (658-666)

http://ejournal.stkip-pgri-sumbar.ac.id/index.php/horizon android, kendala selanjutnya yaitu masalah koneksi internet yang lambat dan menghabiskan kouta internet dengan cepat. Hal ini mengakibatkan beberapa materi yang kurang jelas, tetapi guru selalu mengulang apabila koneksi kurang baik. Pembelajaran Daring ini belum cukup efektif dalam hal penyampaikan materi dan tugas yang harus diselesaikan. Hanya siswa yang memiliki kemampuan akademik tinggi yang bisa mengerjakan tugas yang diberikan. sedangkan siswa yang yang memiliki kemampuan sedang dan rendah itu ada yang mengerjakan tetapi banyak yang salah serta ada yang tidak mengerjakan sama sekali tugas yang diberikan.

Berdasarkan yang telah dipaparkan tentang kemampuan pemahaman konsep matematis di atas menunjukkan bahwa kemampuan pemahaman konsep siswa yang rendah adalah salah satu hal yang berpengaruh terhadap hasil belajar siswa. Dampak dari hal itu dapat dilihat pada rendahnya hasil ulangan harian siswa kelas XI IIS SMA PGRI 3 Padang menunjukkan bahwa banyak siswa yang berada di bawah Kriteria Ketuntasan Minimum (KKM).

Berdasarkan permasalahan yang telah diuraikan di atas untuk mengetahui kemampuan pemahaman konsep siswa lebih lanjut dilakukan penelitian dengan judul Analisis kemampuan Pemahaman Konsep Matematis Siswa pada pembelajaran Matematika Kelas XII IIS SMA PGRI 3 Padang.

\section{METODE PENELITIAN}

Penelitian ini dilaksanakan pada semester Genap hari Kamis Tanggal 3 Juni 2021 di kelas XI IIS SMA PGRI 3 Padang tahun pembelajaran 2020/2021. Jenis penelitian yang digunakan adalah penelitian deskriptif dengan menggunakan pendekatan kualitatif. Subjek penelitian pada penelitian ini adalah siswa kelas XI IIS SMA PGRI 3 Padang yang berjumlah 19 siswa. Instrumen penelitian yang digunakan adalah tes kemampuan pemahaman konsep matematis dan wawancara.

Teknik pengumpulan data yang dilakukan yaitu metode tes dan metode wawancara. Metode tes, data 


\section{Jupana HORIZON}

PENDIDIKAN
JURNAL HORIZON PENDIDIKAN

Publish by: Library of STKIP PGRI Sumatera Barat

E-ISSN : 2775-5770

Vol. 1 No. 4 (November 2021) (658-666)

http://ejournal.stkip-pgri-sumbar.ac.id/index.php/horizon

yang diharapkan berupa hasil pekerjaan siswa pada lembar jawaban yang disertai langkahlangkah. Metode wawancara digunakan sebagai data pendukung hasil tes pemahaman konsep matematis siswa.

Teknik analisis data yang dilakukan yaitu analisis hasil tes kemampuan pemahaman konsep dan wawancara. Analisis hasil tes menggunakan rubrik analitik skala 4 (empat) dan menggunakan kualifikasi skor tes dengan kriteria tinggi, sedang, kurang, dan rendah. Analisis wawancara dianalisis secara kualitatif. Analisis penelitian juga menggunakan trianggulasi data. Trianggulasi dilakukan dengan memanfaatkan penggunaan sumber, yakni dengan membandingkan dan mengecek baik derajat kepercayaan suatu informasi yang diperoleh melalui waktu dan alat yang berbeda dalam penelitian kualitatif.

Kualifikasi hasil $=\frac{\text { jumlah skor yang diperoleh }}{\text { jumlah skor maksimum }} \times 100 \%$ Kualifikasi perindikator $=\frac{\text { skor rata }- \text { rato }}{\text { skor ideal }} \times 100 \%$

\section{HASIL DAN PEMBAHASAN}

Hasil penelitian yang dilakukan sebanyak 19 siswa dengan memberikan 4 butir soal yang mencakup indikator pemahaman konsep yang telah diselesaikan siswa diperoleh data kemampuan pemahaman konsep matematis siswa, untuk mengetahui kemampuan pemahaman konsep matematis siswa lebih dalam lagi dilakukan wawancara. Wawancara dilakukan kepada siswa yang telah mengikuti tes kemampuan pemahaman konsep yang diambil masing-masing 1 siswa dari kategori tinggi, 2 siswa kategori sedang, dan 2 siswa kategori kurang. Sedangkan kemampuan pemahaman konsep kategori rendah tidak ada. Dimana wawancara tersebut mewakili indikator pemahaman konsep siswa lainnya pada kriteria tersebut.

Kemampuan pemahaman konsep matematis siswa dalam penelitian ini didasarkan pada 6 indikator pemahaman konsep yaitu menyatakan ulang sebuah konsep, mengklasifikasi objek-objek menurut sifat tertentu (sesuai dengan konsepnya), memberi contoh dan 


\section{Jupana HORIZON} PENDIDIKAN
JURNAL HORIZON PENDIDIKAN

Publish by: Library of STKIP PGRI Sumatera Barat

E-ISSN : 2775-5770

Vol. 1 No. 4 (November 2021) (658-666)

http://ejournal.stkip-pgri-sumbar.ac.id/index.php/horizon non contoh, menyajikan konsep

dalam bentuk representasi matematis, mengembangkan syarat perlu atau syarat cukup suatu konsep, dan mengaplikasikan konsep atau olgaritma pada pemecahan masalah.

Kemampuan pemahaman konsep matematis siswa dilihat dari kategori, pertama yaitu kategori tinggi terdapat 1 siswa dari 19 siswa dengan ratarata 5\%. Kemampuan pemahaman konsep matematis siswa disini memiliki kemampuan yang baik, dimana siswa mampu menguasai 6 indikator kemampuan pemahaman konsep matematis. Kemampuan pemahaman konsep matematis siswa yang kedua yaitu kategori sedang terdapat 8 siswa dari 19 siswa dengan rata-rata $42 \%$. Kemampuan pemahaman konsep matematis siswa disini memiliki kemampuan sedang, dimana siswa hanya mampu menguasai 3-4 indikator kemampuan pemahaman konsep matematis. Kemampuan pemahaman konsep matematis siswa ketiga yaitu kategori rendah terdapat 10 siswa dari 19 siswa dengan rata-rata $53 \%$. Kemampuan pemahaman konsep matematis siswa disini memiliki kemampuan rendah, dimana siswa hanya mampu menguasai 1-2 indikator kemampuan pemahaman konsep matematis siswa. Sedangkan kemampuan pemahaman konsep rendah tidak ada.

Kemampuan pemahaman konsep matematis siswa kelas XI IIS SMA PGRI 3 Padang, berdasarkan analisis setiap indikator pemahaman konsep adalah sebagai berikut, pada indikator menyatakan ulang sebuah konsep dengan kategori sedang, indikator mengklasifikasikan objekobjek menurut sifat-sifat tertentu (sesuai dengan konsepnya) dengan kategori tinggi, indikator memberikan contoh dan non contoh dari konsep kategori kurang, indikator menyajikan konsep dalam bentuk representasi matematis dengan kategori kurang, indikator mengembangkan syarat perlu atau syarat cukup dari suatu konsep dengan kategori sedang, dan indikator mengaplikasikan konsep atau algoritma pemecahan masalah dengan kategori rendah.

Berdasarkan hasil yang peneliti temukan di lapangan bahwa secara keseluruhan kemampuan pemahaman 


\section{Jupana HORIZON} PENDIDIKAN
JURNAL HORIZON PENDIDIKAN

Publish by: Library of STKIP PGRI Sumatera Barat

E-ISSN : 2775-5770

Vol. 1 No. 4 (November 2021) (658-666)

http://ejournal.stkip-pgri-sumbar.ac.id/index.php/horizon konsep matematis kelas XII IIS SMA

PGRI 3 Padang memiliki niali skor rata-rata kemampuan pemahaman konsep matematis adalah 37,47 dari skor ideal 75 atau $50 \%$ dengan kategori sedang. Akan tetapi pada indikator pemahaman konsep secara keseluruhan masih dikatakan rendah, yang mana siswa masih belum bisa menguasai indikator kemampuan pemahaman konsep matematis secara keseluruhan. Ini sesuai dengan pendapat (Yuni Kartika, 2018) yang menyatakan rendahnya kemampuan pemahaman konsep dikarena siswa kurang mampu menjelaskan atau menuangkan kembali konsep yang mereka dapatkan dan menyajikan konsep dalam bentuk representasi matematis sehingga siswa kurang akan kemampuan pemahaman konsep. Hal ini juga sesuai dengan pendapat Hutagalung (Rida, 2020) pemahaman konsep matematis siswa tergolong rendah, hal ini disebabkan karena kebanyakan siswa belum mampu menyelesaikan tes dengan baik.

\section{KESIMPULAN}

Berdasarkan hasil penelitian yang diperoleh dari keseluruhan siswa kemampuan pemahaman konsep matematis siswa dapat dikelompokkan menjadi 4 kategori yaitu kategori tinggi terdapat 1 siswa, untuk kategori sedang terdapat 8 siswa, untuk kategori kurang terdapat 10 siswa. Sedangkan kategori rendah tidak ada. Maka dari itu dapat disimpulkan bahwa hasil keseluruhan kemampuan pemahaman konsep matematis siswa tergolong kategori kurang.

Kemampuan pemahaman siswa kelas XI IIS SMA PGRI 3 Padang dilihat berdasarkan indikator kemampuan pemahaman konsep matematis siswa sebagai berikut: kemampuan pemahaman menyatakan ulang sebuah konsep berada pada kategori sedang, kemampuan pemahaman mengklasifikasikan objek-objek menurut sifat-sifat tertentu (sesuai dengan konsepnya) berada pada kategori tinggi, kemampuan pemahaman memberikan contoh dan non contoh dari konsep berada pada kategori kurang, kemampuan pemahaman 


\section{Juprat HORIZON} PENDIDIKAN
JURNAL HORIZON PENDIDIKAN

Publish by: Library of STKIP PGRI Sumatera Barat

E-ISSN : 2775-5770

Vol. 1 No. 4 (November 2021) (658-666)

http://ejournal.stkip-pgri-sumbar.ac.id/index.php/horizon menyajikan konsep dalam bentuk repsentasi matematis berada pada kategori kurang, kemampuan pemahaman mengembangkan syarat perlu atau syarat cukup dari suatu konsep berada pada kategori sedang, kemampuan pemahaman mengaplikasikan konsep atau algoritma pemecahan masalah berada pada kategori rendah.

\section{DAFTAR PUSTAKA}

Ai Mulyani, Eneng Kurnia Nur Indah, and Angga Permana Satria. 2018. "Analisis Kemampuan Pemahaman Matematis Siswa SMP Pada Materi Bentuk Aljabar." $A i$ Mulyani Eneng Kurnia Nur Indah Angga Permana Satria 7(2): 251-62.

Irma Fitri. (2019). "Pengaruh Penerapan Model Pembelajaran Kooperatif Tipe Numbered Heads Together (NHT) Terhadap Kemampuan Pemahaman Konsep Matematis Berdasarkan Minat Belajar Siswa Sekolah Menengah Pertama (SMP)." JURING (Journal for Research in Mathematics Learning) 2(2): 137.

Iryanti, Puji. (2004). Penilaian Unjuk Kerja. Yogyakarta: Departemen Pendidikan Pendidikan Nasional.
Istikomah, D. A., \& Jana, P. (2016). "Analisis Pemahaman Konsep Matematis Mahasiswa Melalui Pendekatan Pembelajaran Saintifik Dalam Perkuliahan Aljabar Matrik". In Prosiding Seminar Nasional Etnomatnesia (Vol. 4, No. 01. pp. 927-932).

Kemendikbud. (2014). Kurikulum 2013 SMA/MA. Jakarta: Kemendikbud.

Meleong, Lexy. J. (2010). Metodologi Penelitian Kualitatif. Bandung: PT Remaja Rosdakarya.

Nia Gardenia. (2016). "Peningkatan Kemampuan Pemahaman Dan Komunikasi Matematis Siswa Smk Melalui Pembelajaran Konstruktivisme Model Needham Nia." Jurnal Formatif 6(2): 110-18.

Rida Adhari Yanti, ddk. 2020 Analisis Pemahaman Konsep Matematis Siswa SMP Dengan Pembelajaran Daring. Jurnal Inovasi Dan Riset Pendidikan Matematika. Vol.1, No. 3

Rosita, Cita Dwi, Laelasari, and M. Subali Noto. (2014). "Analisis Kemampuan Pemahaman Matematis Mahasiswa Pada Mata Kuliah Aljabar Linear 1." euclid 1(2): 60-69.

Rosmawati, H. 2008. Penggunaan Teknik Probing Untuk Meningkatkan Pemahaman Konsep Matematika Siswa. Skripsi: UPI. 
Publish by: Library of STKIP PGRI Sumatera Barat

E-ISSN : 2775-5770

Vol. 1 No. 4 (November 2021) (658-666)

http://ejournal.stkip-pgri-sumbar.ac.id/index.php/horizon

Sugiyono. (2013). Metode Penelitian Kuantitatif, Kualitatifdan $R$ \& D. Bandung : Alfabeta.

Suraji, Maimunah, and Sehatta Saragih. (2017). "Analisis Kemampuan Pemahaman Konsep Matematis Dan Kemampuan Pemecahan Masalah Matematis Siswa SMP Pada Materi Sistem Persamaan Linear Dua Variabel (SPLDV)." Suska Journal of Mathematics Education 3(2): 130.
Yuni Kartika. 2018. Analisis Kemampuan Pemahaman Konsep Matematis Peserta Didik Kelas VII SMP Pada Materi Bentuk Aljabar. ISSN:2614-6754. ISSN:26143097. Volume 2 Nomor 4 Tahun 2018.

Yusri, Radhya. (2017). "Pengaruh Pendekatan Problem Centered Learning Terhadap Kemampuan Pemahaman Konsep Dan Pemecahan Masalah Matematis Siswa." III(2). 